\title{
Clinical Outcome of Early Enteral Feeding on Patients Post Esophagectomy
}

\author{
Badawy M. Ahmed, Ahmed A. S. Salem \\ South Egypt Cancer Institute, Assiut University, Assiut, Egypt \\ Email: badawy_znatyy@yahoo.co.uk, ahmed_awad721@yahoo.com
}

How to cite this paper: Ahmed, B.M. and Salem, A.A.S. (2017) Clinical Outcome of Early Enteral Feeding on Patients Post Esophagectomy. Journal of Cancer Therapy, 8, 333-340.

https://doi.org/10.4236/jct.2017.84029

Received: December 26, 2016

Accepted: April 18, 2017

Published: April 21, 2017

Copyright (c) 2017 by authors and Scientific Research Publishing Inc. This work is licensed under the Creative Commons Attribution International License (CC BY 4.0).

http://creativecommons.org/licenses/by/4.0/ (c) (i) Open Access

\begin{abstract}
Objectives: Aim of our work is to study the effect of early enteral feeding through either nasoentral or feeding jejunostomy tube post esophagectomy on patients recovery and hospital stay. Background: Postoperative nutrition is a well known aspect of care in recent years and has been shown to decrease the incidence of complications and hospital stay. Enteral nutrition has been shown to be superior to parenteral nutrition as it is more physiological, safer, cheaper and early enteral nutrition has been clearly confirmed to reduce postoperative morbidity. Methods: This is randomized combined retrospective and prospective study that is conducted in surgical oncology department, South Egypt cancer institute, Assiut University; from October 2012 to October 2016. Patients in this study were divided into two groups: group 1 includes patients with feeding jejunostomy and group 2 is patients with nasoenteral tube. Results: 25 Patients included in this study (19 males \& 6 females). All cases were primarily diagnosed as esophageal cancer, middle and lower $1 / 3$ esophagus or proximal gastric carcinoma infiltrating cardia by clinical data associated with abdominal sonar and/or C.T scan and upper endoscopy with biopsy. There was no significant difference in catheter related complications ( $\mathrm{P}$ value $\mathbf{0 . 2 3 8}$ ). There was no operative mortality. Conclusion: Early postoperative enteral nutrition was feasible and safe for patients undergoing esophagectomy. There is no significant difference between NE and FJ. Enteral nutrition either through nasoenteral or feeding jejunostomy is an effective method for postoperative nutritional support in this type of major surgery.
\end{abstract}

\section{Keywords}

Early Enteral Nutrition, Delayed Enteral Nutrition, Esophageal Cancer, Postoperative Complication Early Enteral Feeding, Feeding Jejunostomy, Nasoenteral Feeding, Cancer Esophagus 


\section{Introduction}

Postoperative nutrition is a well known aspect of care in recent years and has been found to decrease the incidence of complications and hospital stay. Enteral nutrition has been shown to be superior to parenteral nutrition as it is more physiological, safer and cheaper [1] [2] [3] [4].

Different methods for postoperative feeding have been presented but the most effective and the safest one for feeding is still unclear and the choice of the rout of enteral feeding is based on the surgeon's preferable for specific technique. The most commonly used route is feeding jejunostomy; but there were many complications related to this technique that have been reported [5]-[10].

Many complications have been documented using the percutaneous methods [7] [8] [9] and in a recent randomized study the nasoenteral method has been reported to be safer in patients after esophagogastrectomy [11].

\section{Aim of the Study}

Aim of our work is to study the effect of early enteral feeding through either nasoentral or feeding jejunostomy tube post esophagectomy on patients recovery and hospital stay.

\section{Patients and Methods}

This is randomized combined retrospective and prospective study was conducted in surgical oncology department, South Egypt cancer institute, Assiut University; from October 2012 to October 2016. Inclusion criteria were as follows: histologically confirmed cancer esophagus, operable and medically fit patients. Exclusion criteria; metastatic tumor, patients refusal and unfit patients.

Study parameters included surgical technique, demographic details, length of hospital stay (LOS), operative time, body mass index (BMI), post operative serum albumin, morbidity and mortality and Postoperative infection.

Operative mortality was defined as death that occurred within 30 days following the primary operation or during the same hospital stay. Operative morbidities were defined as complications that result in additional interventions or procedures or prolonged hospital stay.

All the procedures were performed after obtaining informed consent following explanation of the surgery and complications. This study was approved by our local ethical committee.

Patients in this study were divided into two groups; group (1) including patients with feeding jejunostomy and group (2) patients with nasoentral tube.

\subsection{Clinical Protocol}

We did not have special feeding formula for nasoentral or jejunostomy feeding tube but we usually use filtered juice of the ordinary food and use water regularly after feeding to avoid obstruction of the tube.

On postoperative day 1 , we started tubal feeding at a rate of $20 \mathrm{~mL} / \mathrm{h}$ administered by continuous infusion to avoid abdominal colic and distention then advanced in the rate up to the target daily requirements of the patient, depending on patient tolerance with gradual withdrawal of IV fluids.

On day 6 or 7 of postoperative period, integrity of the anastomosis was con- 
firmed using contrast study, after that the patient is given clear fluids by mouth usually on postoperative day 7 or 8 . Tube feeding is decreased with the advancement of oral feeding and adaptation of the patient to full fluid consistency.

\subsection{Statistical Analysis}

All statistical analyses were performed using the Statistical Package for the Social Sciences $\left(\mathrm{SPSS}^{\circ}\right)$ version 14.0. The differences in the measurement data were compared using the Student's $\mathrm{t}$ test, and comparisons between groups were tested using the $\chi^{2}$ test. $\mathrm{P}$ value $<0.05$ was considered significant.

\section{Results}

Patients included in this study 25 patients ( 19 males \& 6 females) whom collected from archive and cancer registration data base of surgical department in south Egypt cancer institute. All cases primary diagnosed as esophageal cancer, middle and lower $1 / 3$ rd esophagus or proximal gastric carcinoma infiltrating cardia by clinical data associated with abdominal sonar and/or C.T scan and upper endoscopy with biopsy.

In our study there were 25 patients who received early EN (12 patients through NE tube and 13 patients through FJ tube) (Table 1). There were no significant differences in the mean of age, sex, body mass index (BMI), body weight, or serum albumin values between both groups. P value $0.211,0.8950,0.679$, 0.525 and 0.821 respectively. When comparing the difference between the two groups in operative time, blood loss and length of hospital stay also there were no significant difference (Table 1).

When comparing tumor stage between the two groups there was no significant difference (P value 0.607); however, preoperative chemotherapy was significantly more frequent in patients with $\mathrm{NE}$ tube than in patients with $\mathrm{FJ}$ tube $(\mathrm{P}=$ 0.027) (Table 2).

Different types of approach were done for those patients, when comparing frequencies of these approaches in correlation two both groups of enteral feeding there was no significant difference (P value 0.995) (Table 3).

Table 1. Pre- and Peri-Operative Demographic and Clinical Data.

\begin{tabular}{|c|c|c|c|c|}
\hline & Total (25) & $\mathrm{NE}(\mathrm{n}=12)$ & $\mathrm{FJ}(\mathrm{n}=13)$ & $P$ value (t. test) \\
\hline Age (years) & $57 . .5 \pm 5.3$ & $58.9 \pm 1.45$ & $56 \pm 5.35$ & 0.211 \\
\hline Sex & & & & 0.8950 \\
\hline Male & $19(76 \%)$ & $10(83.33 \%)$ & $9(69.23 \%)$ & \\
\hline Female & $6(24 \%)$ & $2(16.66 \%)$ & $4(30.77 \%)$ & \\
\hline BMI & $23.15 \pm 2.75$ & $22.91 \pm 1.45$ & $23.37 \pm 3.62$ & 0.679 \\
\hline BW & $66 \pm 7.37$ & $67 \pm 7.24$ & $65 \pm 7.65$ & 0.525 \\
\hline Albumin (mg/dL) & $4.1 \pm 0.43$ & $4.12 \pm 0.44$ & $4.08 \pm 1.44$ & 0.821 \\
\hline Operative time (min) & $292.8 \pm 36.8$ & $295.83 \pm 35.79$ & $290 \pm 38.94$ & 0.700 \\
\hline Blood loss (mL) & $607 \pm 88.54$ & $597.9 \pm 95$ & $615.38 \pm 85.1$ & 0.634 \\
\hline $\mathrm{LOH}$ & $23.64 \pm 10.84$ & $24.5 \pm 11.75$ & $22.84 \pm 10.33$ & 0.712 \\
\hline
\end{tabular}


Nine $(75 \%)$ patients experienced tube related complications in nasoenteral tube while 12 (92.3\%) patients have complications attributable to the jejunostomy tube itself. No patients required surgery for these complications (Table 4). 3 patients in jejunostomy group with infection at insertion site were treated by repeated dressing and antibiotic. 2 patients in jejunostomy group had leakage which was externally without symptoms or signs of peritonitis and were treated by insertion of another one with larger calibers and fixation by purse string

Table 2. Tumor stage and preoperative chemotherapy.

\begin{tabular}{ccccc}
\hline Stage & Total (25) & NE (12) & FJ (13) & $\begin{array}{c}\text { P value (Chi-square } \\
\text { test) } 0.607\end{array}$ \\
\hline 0 & 2 & 1 & 1 & \\
I & 8 & 3 & 5 & \\
IIA & 4 & 1 & 3 & \\
IIB & 2 & 1 & 1 & \\
III & 7 & 5 & 2 & \\
IVA & 2 & 1 & 1 & \\
IVB & 0 & 0 & 0 & \\
Preop. & & & & \\
chemoradiation & & $3(25 \%)$ & $9(69.23 \%)$ & \\
No & $12(48 \%)$ & $9(75 \%)$ & $4(30.76 \%)$ & \\
Yes & $13(52 \%)$ & & & \\
\hline
\end{tabular}

Table 3. Correlation between different types of approaches and different types of enteral nutrition.

\begin{tabular}{ccccccc}
\hline approach/type & NE & $\%$ & FJ & $\%$ & total & $\begin{array}{c}\text { P value } \\
\text { (chi-square) } 0.995\end{array}$ \\
\hline Transthoracic & 3 & $25 \%$ & 3 & $23 \%$ & 6 & $24 \%$ \\
Transhiatal (2 field) & 4 & $33.33 \%$ & 5 & $38.46 \%$ & 9 & $36 \%$ \\
3 field & 2 & $16.66 \%$ & 2 & $15.38 \%$ & 4 & $16 \%$ \\
Abdominal & 3 & $25 \%$ & 3 & $23 \%$ & 6 & $24 \%$ \\
TOTAL & 12 & $\mathbf{4 8 \%}$ & 13 & $\mathbf{5 2 \%}$ & $\mathbf{2 5}$ & $\mathbf{1 0 0 \%}$ \\
\hline
\end{tabular}

Table 4. Tube related complications.

\begin{tabular}{ccccccc}
\hline $\begin{array}{c}\text { Cath. comp/type of } \\
\text { feeding }\end{array}$ & $\begin{array}{c}\text { NE } \\
(\mathbf{1 2})\end{array}$ & $\%$ & FJ (13) & $\%$ & $\begin{array}{c}\text { Total } \\
\text { (25) }\end{array}$ & $\begin{array}{c}\text { P value } \\
\text { (chi-square) } \mathbf{0 . 2 3 8}\end{array}$ \\
\hline $\begin{array}{c}\text { Dislocation } \\
\text { Obstruction }\end{array}$ & 2 & $25 \%$ & 2 & $23 \%$ & 4 & $\mathbf{1 6 \%}$ \\
$\quad \begin{array}{c}\text { Leakage* } \\
\text { (nfection at insertion } \\
\text { site }\end{array}$ & 0.00 & $0.00 \%$ & 2 & $15.38 \%$ & 2 & $\mathbf{2 8 \%}$ \\
$\begin{array}{c}\text { Tuba removal by } \\
\text { patient }\end{array}$ & 0.00 & $0.00 \%$ & 3 & $23 \%$ & 3 & $\mathbf{8 \%}$ \\
$\quad$ Total & 3 & $41.66 \%$ & 2 & $15.38 \%$ & 5 & $\mathbf{1 2 \%}$ \\
\end{tabular}

- Patients may have more than one complication.

- $\quad{ }^{*}$ Applies only to the jejunostomy group. 
stitches. Tubal obstruction is treated by flushing of the tube with saline or removed and replaced by another one (in one patient of jejunostomy group). Tubal removal by patient was happened after the fifth day in jejunostomy group insertion with another ones were done while in two patients start early oral fluids the third one was in need for feeding jejunostomy as there was anastomotic leakage also in this patient. In general there was no significant difference in the incidence of tube related complications in both groups.

Postoperative complications were found in 21 patients (84\%) and there was no significant difference between nasoenteral group and feeding jejunostomy group ( $\mathrm{P}$ value 0.433 ). Furthermore we divided the complications into non-infectious and infectious. Also there were no differences $(P$ value 0.728$)$ and $(P$ value 0.341 ) respectively. (Table 5 ) There was no operative mortality.

\section{Discussion}

Oesophageal cancers have many bad effects on the immunological and nutritional status of patients. This is due to either oesophageal obstruction or malignant cachexia [2] [3]. These factors in association with the long period of postoperative fasting until healing of the anastomosis raising the question is early postoperative enteral feeding either by a naso-enteral route (NE) or by feeding jejunostomy (FJ) have beneficial on patient recovery. Many studies reviewed the role of early enteral feeding post-esophagectomy and its complications.

Swails et al. [12] were studying 25 patients undergoing oesophagogastrectomy and comparing between enteral feeding through jejunostomy $(\mathrm{n}=13)$ and without jejunostomy by a routine advancement of diet $(n=12)$ (control group). They found that the incidence of anastomotic leaks in the control group presented in three patients while in the jejunal group there was no leak and this difference was not significant. In addition, length of hospital stay and the incidence of infectious complications were similar between both groups. They concluded that even there was no statistically significance of feeding jejunostomy, it was effective and safe, adding only $10 \mathrm{~min}$ to the operative time.

Table 5. Postoperative Complications.

\begin{tabular}{ccccc}
\hline & Total & NE & FJ & P-value (Chi-square test) \\
Postop. complications & 21 & 11 & 10 & 0.433 \\
Non-infectious & 12 & 6 & 6 & 0.728 \\
Tracheal damage & 1 & 1 & 0 & 0.288 \\
Haemorrhage & 4 & 2 & 2 & 0.930 \\
Recurrent nerve palsy & 2 & 1 & 1 & 0.953 \\
Anastomotic dehiscence & 5 & 2 & 3 & 0.689 \\
Infectious & 9 & 5 & 4 & 0.341 \\
Pneumonia & 5 & 4 & 1 & 0.109 \\
Sepsis & 1 & 0 & 1 & 0.327 \\
Wound infection & 3 & 1 & 2 & 0.588 \\
\hline
\end{tabular}

- Patients may have more than one complication. 
28 patients undergoing pancreatodudenectomy or oesophagectomy were studied by Watters et al. [13] where they were comparing early postoperative feeding via jejunostomy (13 patients) or no fed (15 patients). They found that there was significant effect of enteral nutrition lowering postoperative vital capacity without statistical significance on FEV1. They attributed that to abdominal distention and impairment of diaphragmatic function. They also found that there was decrease in the postoperative mobility jejunostomy group, and a significant catheter related morbidity requiring laparotomy was presented in one case. However, there were no significant differences between the two groups in the incidence of length of stay in the intensive care and complications.

Another study done by Page et al. [14] on 40 patients undergoing transthoracic surgery for cancer esophagus who received early enteral feeding via NJ tube (20 patients) and a control group given intravenous crystalloid fluid (20 patients); In one patient only, NJ tube was removed due to its adverse effects on expectoration. Overall, there were no significant differences between the two groups, and no measurable benefit of NJ tube over intravenous hydration but concluding that it is safe and well-tolerated for patients undergoing routine oesophagectomy.

Comparison between nasal or percutaneous route of enteral feeding was addressed by Hans [11]. It was prospective randomized study (jej in 79 patients and ND in 71 patients). Results were as follow; Infectious complications Jejunostomy (Jej) group 36 (45\%): Wound infection 5 (6\%), pneumonia 27 (34\%), UTI 4 (5\%). Naso-Duodenostomy (ND) group: 34 (48\%): Wound infections 4 (6\%), pneumonia 29 (41\%), UTI 1 (1\%).

Catheter-related complications: Jej group 31 (38\%): Patient removal 4 (5\%), obstruction $5(6 \%)$, dislocation $5(6 \%)$, infection at insertion site $13(16 \%)$, leakage $3(4 \%)$ and relaparotomy 1 (1\%). ND group 20 (29\%): Patient removal 2 (3\%), obstruction $2(3 \%)$ and dislocation $16(23 \%)$.

Mortality: Jej group 6 (8\%) and ND group 2 (3\%). Deaths in this study were not attributed to catheter-related complications. The incidences of catheter-related complications were frequent in both groups without significant differences, only one patient was in needed for relaparotomy in the jejunostomy group. In general this study concluded that naso-duodenal feeding was as effective as jejunostomy in providing enteral nutrition postesophagectomy.

In our study there were 25 patients who received early EN (12 patients through NE tube and 13 patients through FJ tube). There were no significant differences in the mean of age, sex, body mass index (BMI), body weight, or serum albumin values between both groups. P value $0.211,0.8950,0.679,0.525$ and 0.821 respectively. When comparing the difference between the two groups in operative time, blood loss and length of hospital stay also there were no significant difference.

Nine $(75 \%)$ patients experienced tube related complications in nasoenteral tube while 12 (92.3\%) patients have complications attributable to the jejunostomy tube itself. No patients required surgery for these complications. 3 patients in jejunostomy group with infection at insertion site were treated by repeated dressing and antibiotic. 2 patients in jejunostomy group had leakage which was externally without symptoms or signs of peritonitis and were treated by insertion of another one with larger calibers and fixation by pirse string stitches. 
Tubal obstruction is treated by flushing of the tube with saline or removed and replaced by another one (in one patient of jejunostomy group). Tubal removal by patient was happened after the fifth day in jejunostomy group; treated by insertion with another one were done while in two patients start early oral fluids, the third one was in need for feeding jejunostomy as there was anastomotic leakage also in this patient.

In general there was no significant difference in the incidence of tube related complications in both groups. Postoperative complications were found in $21 \mathrm{pa}-$ tients $(84 \%)$ and there was no significant difference between nasoenteral group and feeding jejunostomy group ( $\mathrm{P}$ value 0.433 ). Furthermore we divided the complications into non-infectious and infectious, Also there were no differences ( $P$ value 0.728 ) and (P value 0.341$)$ respectively. In our study there was no operative mortality.

\section{Conclusion}

Early postoperative enteral nutrition was feasible and safe for patients undergoing esophagectomy. There is no significant difference between NE and FJ. Enteral nutrition either through nasoenteral or feeding jejunostomy is an effective method for postoperative nutritional support in this type of major surgery. From physiological point of view, enteral nutrition enhances bacterial flora and protects intestinal barrier and plays an important role in reducing the incidence of postoperative infection.

\section{Conflict of Interest}

We have no conflicts of interest or financial ties to disclose.

\section{References}

[1] Moore, F.A., Feliciano, D.V., Andrassy, R.J., McArdle, A.H., Booth, F.V., Morgenstein-Wagner, T.B., et al. (1992) Early Enteral Feeding, Compared with Parenteral, Reduces Postoperative Septic Complications. The Results of a Meta-Analysis. Annals of Surgery, 216, 172-183. https://doi.org/10.1097/00000658-199208000-00008

[2] Mazaki, T. and Ebisawa, K. (2008) Enteral versus Parenteral Nutrition after Gastrointestinal Surgery: A Systematic Review and Meta-Analysis of Randomized Controlled Trials in the English Literature. Journal of Gastrointestinal Surgery, 12, 739-755. https://doi.org/10.1007/s11605-007-0362-1

[3] Jeejeebhoy, K.N. (2007) Enteral Nutrition versus Parenteral Nutrition-The Risks and Benefits. Nature Clinical Practice Gastroenterology \& Hepatology, 4, 260-265.

[4] Bozzetti, F., Braga, M., Gianotti, L., Gavazzi, C. and Mariani, L. (2001) Postoperative Enteral versus Parenteral Nutrition in Malnourished Patients with Gastrointestinal Cancer: A Randomised Multicentre Trial. The Lancet, 358, 1487-1492.

[5] Smith, C.D. and Sarr, M.G. (1991) Clinically Significant Pneumatosis Intestinalis with Postoperative Enteral Feedings by Needle Catheter Jejunostomy: An Unusual Complication. Journal of Parenteral and Enteral Nutrition, 15, 328-331. https://doi.org/10.1177/0148607191015003328

[6] Myers, J.G., Page, C.P., Stewart, R.M., Schwesinger, W.H., Sirinek, K.R. and Aust, J.B. (1995) Complications of Needle Catheter Jejunostomy in 2,022 Consecutive Applications. The American Journal of Surgery, 170, 547-550. 
[7] Holmes, J.H., Brundage, S.I., Yuen, P., Hall, R.A., Maier, R.V. and Jurkovich, G.J. (1999) Complications of Surgical Feeding Jejunostomy in Trauma Patients. The Journal of Trauma, 47, 1009-1012. https://doi.org/10.1097/00005373-199912000-00004

[8] De Gottardi, A., Krähenbühl, L., Farhadi, J., Gernhardt, S., Schäfer, M. and Büchler, M.W. (1999) Clinical Experience of Feeding through a Needle Catheter Jejunostomy after Major Abdominal Operations. European Journal of Surgery, 165, 1055 1060. https://doi.org/10.1080/110241599750007892

[9] Sonawane, R.N., Thombare, M.M., Kumar, A., Sikora, S.S., Saxena, R., Kapoor, V.K. and Kaushik, S.P. (1997) Technical Complications of Feeding Jejunostomy: A Critical Analysis. Tropical Gastroenterology, 18, 127-128.

[10] Ryan, A.M., Rowley, S.P., Healy, L.A., Flood, P.M., Ravi, N. and Reynolds, J.V. (2006) Post-Oesophagectomy Early Enteral Nutrition via a Needle Catheter Jejunostomy: 8-Year Experience at a Specialist Unit. Clinical Nutrition, 25, 386-393.

[11] Hans-Geurts, I.J., Hop, W.C., Verhoef, C., Tran, K.T. and Tilanus, H.W. (2007) Randomized Clinical Trial Comparing Feeding Jejunostomy with Nasoduodenal Tube Placement in Patients Undergoing Oesophagectomy. British Journal of Surgery, 94, 31-35. https://doi.org/10.1002/bjs.5283

[12] Swails, W.S., Babineau, T.J., Ellis, F.H., Kenler, A.S. and Forse, R.A. (1985) The Role of Enteral Jejunostomy Feeding after Esophagogastrectomy: A Prospective, Randomized Study. Diseases of the Esophagus, 8, 193-199. https://doi.org/10.1093/dote/8.3.193

[13] Watters, J.M., Kirkpatrick, S.M., Norris, S.B., Shamji, F.M. and Wells, G.A. (1997) Immediate Postoperative Enteral Feeding Results in Impaired Respiratory Mechanics and Decreased Mobility. Annals of Surgery, 226, 369-380. https://doi.org/10.1097/00000658-199709000-00016

[14] Page, R.D., Oo, A.Y., Russell, G.N. and Pennefather, S.H. (2002) Intravenous Hydration versus Naso-Jejunal Enteral Feeding after Esophagectomy: A Randomized Study. European Journal of Cardio- Thoracic Surgery, 22, 666-672.

\section{Submit or recommend next manuscript to SCIRP and we will provide best} service for you:

Accepting pre-submission inquiries through Email, Facebook, LinkedIn, Twitter, etc. A wide selection of journals (inclusive of 9 subjects, more than 200 journals)

Providing 24-hour high-quality service

User-friendly online submission system

Fair and swift peer-review system

Efficient typesetting and proofreading procedure

Display of the result of downloads and visits, as well as the number of cited articles

Maximum dissemination of your research work

Submit your manuscript at: http://papersubmission.scirp.org/

Or contact jct@scirp.org 